\title{
Laparoscopic versus Open Total Mesorectal Excision: A Comparative Study on Short-Term Outcomes
}

\author{
A Single-Institution Experience regarding Anterior Resections and \\ Abdominoperineal Resections
}

\author{
A.A.F.A. Veenhof ${ }^{a} \quad$ A.F. Engel ${ }^{d} \quad$ M.E. Craanen ${ }^{b} \quad$ S. Meijer ${ }^{a}$ \\ E.S.M. de Lange-de Klerk ${ }^{c}$ D.L. van der Peet ${ }^{a} \quad$ W.J.H.J. Meijerink ${ }^{a} \quad$ M.A. Cuesta ${ }^{a}$ \\ Departments of a Surgery, ${ }^{\mathrm{b}}$ Gastroenterology, and ${ }^{\mathrm{c} C l i n i c a l}$ Epidemiology and Biostatistics, Vrije Universiteit \\ Medical Center, Amsterdam, d Department of Surgery, Zaans Medical Center, Zaandam, The Netherlands
}

\section{Key Words}

Laparoscopy · Total mesorectal excision • Rectal cancer • Laparoscopic rectal excision · Cancer

\begin{abstract}
Background: Laparoscopic total mesorectal excision (TME) is being used in rectal cancer more frequently. The aim of this study was to analyze the differences in short-term outcomes between open and laparoscopic TME. Methods: In this nonrandomized consecutive study, the short-term outcomes of 100 patients undergoing TME for proven rectal cancer were analyzed. Results: Two groups of 50 patients underwent an open or laparoscopic TME for rectal cancer. Both groups were comparable. Laparoscopic surgery took longer to perform (250 vs. $197.5 \mathrm{~min}, \mathrm{p}<0.01$ ), but was accompanied by less blood loss (350 vs. $800 \mathrm{ml}, \mathrm{p}<0.01$ ). Enteric function recovered sooner after laparoscopy. The numbers of major and minor complications were comparable between both groups, although fewer patients had major complications in the laparoscopic group (6 vs. 15 patients, $p=0.03$ ). Hospital stay was shorter for patients who underwent a laparoscopic abdominoperineal resection (10 vs. 12 days, $p=0.04$ ). Median follow-up was 17 months for the lap-
\end{abstract}

aroscopic group and 22 months for the open group. Survival analyses between the groups showed no statistical difference in disease-free and overall survival. Conclusion: This study shows that laparoscopic TME for rectal cancer is a safe and feasible technique with some short-term benefits over open TME.

Copyright $\odot 2007$ S. Karger AG, Basel

\section{Introduction}

Since its introduction in 1982, the total mesorectal excision (TME) concept by Heald et al. [1] has become the gold standard in surgical treatment of rectal cancer $[2,3]$. It includes the standard excision of the total mesorectum, through the avascular 'holy plane', removing potential micrometastases enclosed in the mesorectum. At present, TME in combination with preoperative radiation therapy offers the lowest local recurrence rate $(<5 \%)$ and the highest 5 -year survival rate $(80 \%)$ in patients with midand low-rectal cancer $[4,5]$.

There are however problems with open TME surgery, mainly pertaining to difficulties in pelvic dissection, often leading to functional urogenital problems - especial-

\section{KARGER}

Fax +4161306 1234 E-Mail karger@karger.ch www.karger.com

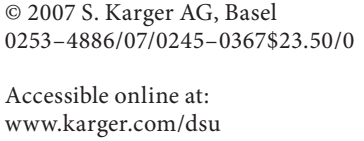

Miguel A. Cuesta

Department of Surgery, Vrije Universiteit Medical Center

Post bus 7057

NL-1007 MB Amsterdam (The Netherlands)

Tel. +31 20444 4781, Fax +31 20444 4511, E-Mail ma.cuesta@vumc.nl 
ly in male patients - and possibly a less radical resection. Moreover, the increased use of coloanal anastomosis has also increased the need for better visualization during pelvic dissection. The laparoscopic approach to rectal cancer may be an attractive alternative for open TME because it offers better visualization, more delicate instrumentation and better tissue handling. This in turn, may lead to an adequate dissection up to the pelvic floor in combination with a better preservation of the hypogastric plexus and erigent nerves, possibly resulting in an improved functional and oncological outcome.

Several recently published randomized studies have shown short-term benefits of the laparoscopic approach to colon cancer over the open approach, without compromising oncological outcome [6-9]. Hence, we performed a study to compare laparoscopic TME with open TME in terms of perioperative and oncological outcomes in patients with rectal cancer.

\section{Materials and Methods}

\section{Patients}

In April 2002, a laparoscopic TME trial was started at the Vrije Universiteit Medical Center (VUmc), with a planned evaluation after approximately 3 years. Subsequently, a series of 50 consecutive patients who underwent conventional open TME with curative intent for rectal cancer, operated just before the laparoscopic TME trial was initiated, was compared with a group of 50 consecutive patients who underwent laparoscopic TME for rectal cancer. The conventional group included patients who were operated on in the pre-laparoscopic period between February 1999 and April 2002, whereas the laparoscopic group included patients who were operated on between April 2002 and November 2005.

Patients with previous abdominal surgery via median laparotomy were excluded from this study, as were patients undergoing palliative surgery or surgery for benign tumors. No fast-track postoperative recovery programs were used in either group. $\mathrm{Pa}$ tients from both groups were operated on by the same surgical team from the VUmc with extensive previous laparoscopic experience in colectomies (participants in the COLOR I trial), palliative rectal resections and esophageal resections for cancer.

All patients received the same pretreatment workup, including a colonoscopy with biopsies, MRI or rectal endoscopic ultrasound for local staging, and an abdominal CT scan, chest X-ray and carcinoembryonic antigen level for dissemination status. Tumors had to be located within $17 \mathrm{~cm}$ of the anal verge, measured by rigid scope, and were defined according to Goligher [10]: $7 \mathrm{~cm}$ or less from the anal verge $=$ low rectum; over $7 \mathrm{~cm}$ but less than or equal to $12 \mathrm{~cm}$ = mid-rectum; over $12 \mathrm{~cm}$ but less than or equal to $17 \mathrm{~cm}=$ high rectum.

\section{Surgical Technique}

Laparoscopic TME. Using a 6-trocar approach the inferior mesenteric vessels were taken down with left ureter identification, followed by retromesenteric dissection from medial to lateral.
Going up, the splenic flexure was mobilized, followed by laparoscopic TME dissection with preservation of the hypogastric plexus and nerves. Following the principles of the TME, three different operations were performed:

For tumors in the high rectum $(12-17 \mathrm{~cm})$, a high TME or partial mesorectal excision was performed laparoscopically with transection of the mesorectum $5 \mathrm{~cm}$ distal of the tumor, followed by a double-stapled anastomosis.

For tumors located in the mid- $(7-12 \mathrm{~cm})$ and distal rectum (anal verge to $7 \mathrm{~cm}$ ), a complete TME was performed laparoscopically, after splenic flexure mobilization. Hereafter, the rectum was transected with an endoscopic or conventional stapler through a Pfannenstiel incision at the level of the pelvic floor (with at least a $2-\mathrm{cm}$ distal margin from the tumor). A transanal coloanal anastomosis was performed if at least $1 \mathrm{~cm}$ from the dentate line could be spared with an adequate oncological distal margin of $2 \mathrm{~cm}$. Higher anastomoses were double stapled.

An abdominoperineal resection without mobilization of the splenic flexure was considered appropriate for tumors with sphincter involvement, a margin of less than $3 \mathrm{~cm}$ to the dentate line thus making a coloanal anastomosis impossible and in patients with sphincter dysfunction making a functional outcome after a coloanal anastomosis unlikely.

Protective loop ileostomy was left to the discretion of the surgeon. In our institution a liberal policy concerning protective loop ileostomies is maintained. In patients with a mid- or low anastomosis, or in the case of marginal donuts, a diversion of fecal load is created.

Open TME. Open TME was performed according to previously described techniques [11].

\section{Collected Data}

- Patient data: age, body mass index and preoperative morbidity.

- Perioperative data: operating time, blood loss and complications.

- Postoperative data: length of hospital stay (including preoperative night spent in hospital), time to first liquid intake, time to unrestricted food intake, time to first stool passage and postoperative complications.

- Pathology data: Astler-Coller classification, total number of lymph nodes harvested, length of the resected specimen, tumor diameter, tumor distance to distal resection margin and circumferential margin status.

- Follow-up: time to local recurrence, time to occurrence of distant metastases, overall survival (OS) and disease-free survival (DFS) were noted.

Patients with low- and mid-rectum tumors (T2 and T3) received neoadjuvant therapy as depicted in table 1 .

Statistical Analysis

Statistical analysis was performed using the SPSS software package (SPSS 11.5 for Windows; SPSS, Chicago, Ill., USA). All data were analyzed according to the 'intention-to-treat' principle. Medians and interquartile ranges were calculated and subsequently depicted when appropriate. The Mann-Whitney U test, $\chi^{2}$ test or Fisher's exact test were applied when appropriate for group comparisons. Survival curves were obtained using the KaplanMeier method. Survival of both groups was compared with the $\log$-rank test. Significance was set at $\mathrm{p}<0.05$. 


\section{Results}

\section{Patient and Tumor Characteristics}

Patient characteristics are depicted in table 1. The laparoscopic group $(n=50)$ included 28 men and 22 women with a median age of 67 years (interquartile range: $58-$ $75)$. The open group $(n=50)$ included 32 men and 18 women with a median age of 64.5 years (interquartile range: $56-72 ; \mathrm{p}=0.21$ ). The median body mass index for the laparoscopic group was 25 (interquartile range: $23-$ 27) and for the open group 26 (interquartile range: $23-27$; $\mathrm{p}=0.43)$. The median distance between tumor and anal verge was $8.0 \mathrm{~cm}$ (range: $2-17$ ) in the laparoscopic group and $10.0 \mathrm{~cm}$ (range: $2-15)$ in the open group $(\mathrm{p}=0.81)$. In each group 26 patients (52\%) underwent neoadjuvant radiation therapy. In the laparoscopic group 2 patients (4\%) also received neoadjuvant chemotherapy. The median delay between the last dose of radiation therapy and surgery was 44.5 days (interquartile range: 9-52) for the laparoscopic group and 42 days (interquartile range: 14-49) for the open group ( $\mathrm{p}=0.74)$.

In the laparoscopic group, 34 (68\%) of the patients underwent a TME with primary anastomosis, including 10 patients with a coloanal anastomosis because of very distal cancer in the rectum. The other 16 (32\%) patients underwent an abdominoperineal resection. In the open group, 33 patients $(66 \%)$ underwent a TME with primary anastomosis, and 17 (34\%) an abdominoperineal resection.

\section{Operative Data}

Operative data are listed in table 2. The median operating time for laparoscopic operations was longer than for open procedures (250 vs. $197.5 \mathrm{~min}, \mathrm{p}<0.01$ ). Median blood loss was less in the laparoscopic group (350 vs. 800 $\mathrm{ml}, \mathrm{p}<0.01)$. Operative complications occurred in $1 \mathrm{pa}-$ tient $(2 \%)$ of the laparoscopic group and in 9 patients $(18 \%)$ of the open group $(\mathrm{p}=0.01)$.

A diverting loop ileostomy was performed in 18 of 34 patients (53\%) with a primary anastomosis in the laparoscopic group, and in 15 of 33 patients (46\%) with a primary anastomosis in the open group $(p=0.54)$.

The laparoscopic procedure was converted to an open procedure in 4 patients ( $8 \%$ ). In all of these patients, colonic dissection, and in 1 patient rectal dissection, was performed by means of laparoscopy. Two conversions were necessary due to the combination of a narrow male pelvis and a large tumor, 1 conversion due to adhesions around the splenic flexure (thus preventing proper mobilization), and 1 conversion due to extreme obesity. The
Table 1. Patient and tumor characteristics

\begin{tabular}{|c|c|c|c|}
\hline Variable & $\begin{array}{l}\text { Laparoscopic } \\
\text { TME }(\mathrm{n}=50)\end{array}$ & $\begin{array}{l}\text { Open TME } \\
(\mathrm{n}=50)\end{array}$ & $\begin{array}{l}\mathrm{p} \\
\text { value }\end{array}$ \\
\hline Gender & & & 0.41 \\
\hline Male & $28(56)$ & $32(64)$ & \\
\hline Female & $22(44)$ & $18(36)$ & \\
\hline Age, years & & & 0.21 \\
\hline Median & 67 & 64.5 & \\
\hline Interquartile range & $58-75$ & $56-72$ & \\
\hline Body mass index & & & 0.43 \\
\hline Median & 25 & 26 & \\
\hline Interquartile range & $23-27$ & $23-27$ & \\
\hline Previous abdominal surgery & $12(24)$ & $21(42)$ & 0.06 \\
\hline Cardiovascular disease & $19(38)$ & $16(32)$ & 0.53 \\
\hline Other systemic disease & $5(10)$ & $3(6)$ & 0.72 \\
\hline Preoperative tumor staging & & & 0.43 \\
\hline $\mathrm{T} 1$ & $1(2)$ & $1(2)$ & \\
\hline $\mathrm{T} 2$ & $7(14)$ & $6(12)$ & \\
\hline T3 & $26(52)$ & $19(38)$ & \\
\hline $\begin{array}{c}\text { Tumor inaccessible to rectal } \\
\text { ultrasound evaluation }\end{array}$ & $16(32)$ & $24(48)$ & \\
\hline Median distance from anal & & & \\
\hline verge to tumor, $\mathrm{cm}$ & 8.0 & 10.0 & 0.81 \\
\hline Range & $2-17$ & $2-15$ & \\
\hline Tumor localization & & & 0.26 \\
\hline High rectum & $13(26)$ & $8(16)$ & \\
\hline Mid-rectum & $14(28)$ & $21(42)$ & \\
\hline Low rectum & $23(46)$ & $21(42)$ & \\
\hline Neoadjuvant therapy & & & 0.53 \\
\hline 5 fractions of $5 \mathrm{~Gy}$ & $22(44)$ & $23(46)$ & \\
\hline 28 fractions of $1.8 \mathrm{~Gy}$ & $2(4)$ & $3(6)$ & \\
\hline Chemoradiation & $2(4)$ & $0(0)$ & \\
\hline
\end{tabular}

Values are shown as numbers with percentages in parentheses, unless otherwise indicated.

data regarding converted patients was analyzed with the laparoscopic group in an intention-to-treat analysis.

One of the 4 converted patients required secondary surgery after 9 days following the initial surgery due to an infected hematoma. Although the surgery was technically without complications, the patient died perioperatively due to cardiac ischemia. The other 3 patients recovered quickly without any major complications.

\section{Postoperative Data}

Postoperative data are shown in table 3. Return of bowel function (liquid intake, unrestricted food intake and passage of stool) occurred sooner in the laparoscopic group. Median hospital stay in the present study included 
Table 2. Operative data and complications

\begin{tabular}{lccr}
\hline Variable & $\begin{array}{c}\text { Laparoscopic } \\
\text { TME }(\mathrm{n}=50)\end{array}$ & $\begin{array}{l}\text { Open TME } \\
(\mathrm{n}=50)\end{array}$ & p value \\
\hline Operating time, min & $250[210-285]$ & $197.5[165-220]$ & $<0.01$ \\
Anterior resections & $242.5[200-267]$ & $175[160-215]$ & $<0.01$ \\
Abdominoperineal resections & $287.5[253-322.5]$ & $205[180-230]$ & $<0.01$ \\
Blood loss, ml & $350[150-700]$ & $800[510-1,000]$ & $<0.01$ \\
Anterior resections & $300[130-500]$ & $700[500-950]$ & $<0.01$ \\
Abdominoperineal resections & $700[225-1,050]$ & $950[800-1,500]$ & 0.03 \\
Operative complications & $1(2)$ & $9(18)$ & 0.01 \\
Anterior resections & $1(2)$ & $7(21)$ & 0.03 \\
Abdominoperineal resections & $0(0)$ & $2(12)$ & 0.48 \\
Intra-abdominal bleeding & $0(0)$ & $4(8)$ & \\
Ureter damage & $1(2)$ & $2(4)$ & \\
Rectum perforation & $0(0)$ & $1(2)$ & \\
Small bowel perforation & $0(0)$ & $15(46)$ & \\
Total protective loop ileostomies & $18(53)$ & $11(13)$ & \\
High rectums $(12-17 \mathrm{~cm})$ & 0 & $3(75)$ & \\
Mid-rectums $(7-12 \mathrm{~cm})$ & $10(66)$ & & \\
Low rectums $(0-7 \mathrm{~cm})$ & $8(100)$ & & \\
\hline
\end{tabular}

Values are shown as numbers with percentages in parentheses, or medians with interquartile ranges in square brackets. the preoperative night spent in hospital and did not differ significantly between groups. Only patients undergoing laparoscopic abdominoperineal resections had a significantly shorter hospital stay (10 vs. 12 days, $\mathrm{p}=0.04$ ).

The total number of major complications did not differ significantly between groups or subgroups. However, these major complications occurred in fewer patients in the laparoscopic group ( 6 vs. 15 patients, $\mathrm{p}=0.03$ ), significantly expressed by the abdominoperineal subgroup. The total number of minor complications did not significantly differ between groups or subgroups and occurred in a similar number of patients (13 vs. $17, \mathrm{p}=0.38$ ).

Anastomotic leakage was found in 5 patients (15\%) in the laparoscopic group and in 3 patients (9\%) in the open group. A pelvic abscess was found in none of the patients in the laparoscopic group and in 2 patients (4\%) in the open group. Mortality was $2 \%$ (1 patient) in each group.

Secondary surgery within 30 postoperative days was necessary in 7 patients (14\%) in both groups.

\section{Pathology Specimen}

Tumor classification is shown in table 4. No significant difference in the median number of harvested lymph nodes was observed between the laparoscopic and the open group (7 vs. $6, \mathrm{p}=0.65$ ).

On average, a significantly longer bowel segment was resected in the open group ( 28 vs. $22 \mathrm{~cm}, \mathrm{p}<0.01$ ), but not in the abdominoperineal resection subgroup (27.5 vs. $36 \mathrm{~cm}, \mathrm{p}=0.09$ ). Tumors were larger in the open group ( 40 vs. $25 \mathrm{~mm}, \mathrm{p}=0.01$ ), but not in the anterior resection subgroup ( 30 vs. $40 \mathrm{~mm}, \mathrm{p}=0.15$ ). The median distances between tumor and distal resection margin were similar for the laparoscopic and the open group (30 vs. $32.5 \mathrm{~mm}$, $\mathrm{p}=0.61$ ). A circumferential margin of $2 \mathrm{~mm}$ or more was achieved in $92 \%$ of cases in both groups.

\section{Follow-Up Data}

The median follow-up was 17 months (interquartile range: 6-26) for patients treated with laparoscopic resection and 22 months (interquartile range: 10-38) for patients treated with open resection. Kaplan-Meier analyses for OS and DFS are depicted in figures 1 and 2, respectively. OS at 36 months was $98 \%$ (95\% CI: 56-100) for the laparoscopic group and 72\% (95\% CI: 56-88) for the open group ( $\mathrm{p}=0.08)$. DFS at 36 months was $79 \%$ (95\% CI: 63-96) for the laparoscopic group and 57\% (95\% CI: 40$74)$ for the open group $(p=0.08)$. Separate analysis of the anterior and abdominoperineal resection subgroups yielded no statistical differences in OS or DFS.

Two patients (4\%) in the laparoscopic group and 6 (12\%) in the open group presented with a local recurrence $(\mathrm{p}=0.14)$. Five patients in the laparoscopic group and 10 in the open group presented with distant metastases $(\mathrm{p}=$ 0.16 ). No portsite recurrences were found in this study. 
Table 3. Postoperative data including complications within 30 days

\begin{tabular}{|c|c|c|c|}
\hline Variable & $\begin{array}{l}\text { Laparoscopic } \\
\text { TME }(\mathrm{n}=50)\end{array}$ & $\begin{array}{l}\text { Open TME } \\
(\mathrm{n}=50)\end{array}$ & $\mathrm{p}$ value \\
\hline Hospital stay, days & $10.5[8-14]$ & $12[9-15]$ & 0.22 \\
\hline Anterior resections & $11.5[7-15]$ & $11[9-14]$ & 0.84 \\
\hline Abdominoperineal resections & $10[8.5-11.5]$ & $12[10-18.5]$ & 0.04 \\
\hline First liquid intake, days & $1[1-2]$ & $2[1-3]$ & $<0.01$ \\
\hline Anterior resections & $1[1-2]$ & $2[1-2.5]$ & 0.02 \\
\hline Abdominoperineal resections & $1[1-1.5]$ & $2[2-3]$ & $<0.01$ \\
\hline Unrestricted food intake, days & $4[4-5.5]$ & $6[5-7]$ & $<0.01$ \\
\hline Anterior resections & $4[4-5]$ & $6[4-8]$ & $<0.01$ \\
\hline Abdominoperineal resections & $4.5[4-6]$ & $6[5-7]$ & 0.09 \\
\hline First stool, days & $4[3-5]$ & $5[4-6]$ & $<0.01$ \\
\hline Anterior resections & $4[3-5]$ & $6[4-6]$ & $<0.01$ \\
\hline Abdominoperineal resections & $4[3-5]$ & $5[4.5-6]$ & 0.02 \\
\hline Mortality & $1(2)$ & $1(2)$ & 1.0 \\
\hline Major complications & $10(20)$ & $16(32)$ & 0.17 \\
\hline Anterior resections & $10(29)$ & $14(42)$ & 0.27 \\
\hline Abdominoperineal resections & $0(0)$ & $2(12)$ & 0.49 \\
\hline Intra-abdominal bleeding & $0(0)$ & $1(2)$ & \\
\hline Anastomosis leak & $5(15)$ & $3(9)$ & \\
\hline Pelvic abscess & $0(0)$ & $2(4)$ & \\
\hline Lung embolism & $1(2)$ & $1(2)$ & \\
\hline Cardiac complaints & $2(4)$ & $5(10)$ & \\
\hline Pneumonia & $1(2)$ & $3(6)$ & \\
\hline Ischemic stoma & $1(2)$ & $1(2)$ & \\
\hline Major complications per patient ${ }^{1}$ & $6(12)$ & $15(30)$ & 0.03 \\
\hline Anterior resections & $6(18)$ & $11(33)$ & 0.14 \\
\hline Abdominoperineal resections & $0(0)$ & $4(24)$ & 0.04 \\
\hline Minor complications & $16(32)$ & $21(42)$ & 0.30 \\
\hline Anterior resections & $7(21)$ & $12(36)$ & 0.37 \\
\hline Abdominoperineal resections & $9(56)$ & $9(53)$ & 0.94 \\
\hline Wound infection & $4(8)$ & $6(12)$ & \\
\hline Perineum infections & $3(6)$ & $2(4)$ & \\
\hline Paralytic ileus & $0(0)$ & $3(6)$ & \\
\hline Urinary tract & $9(18)$ & $10(20)$ & \\
\hline Minor complications per patient ${ }^{1}$ & $13(26)$ & $17(34)$ & 0.38 \\
\hline Anterior resections & $7(21)$ & $11(33)$ & 0.24 \\
\hline Abdominoperineal resections & $6(38)$ & $6(35)$ & 0.90 \\
\hline Secondary surgery & $7(14)$ & $7(14)$ & 1.0 \\
\hline Pelvic abscess drainage & $2(4)$ & $2(4)$ & \\
\hline Anastomosis leak & $3(6)$ & $2(4)$ & \\
\hline Intra-abdominal bleeding & $0(0)$ & $1(2)$ & \\
\hline Ischemic stoma & $1(2)$ & $0(0)$ & \\
\hline Other & $1(2)$ & $2(4)$ & \\
\hline
\end{tabular}

Values are shown as numbers with percentages in parentheses, or medians with interquartile ranges in square brackets.

${ }^{1}$ More than one complication could have occurred per patient.

\section{Discussion}

Since the introduction of laparoscopic colonic surgery in 1991 [12], many questions have arisen concerning the oncological safety of this approach, following reports on portsite metastases [13-15]. Randomized studies, comparing the laparoscopic approach to the open approach in colon cancer, have shown that the laparoscopic approach has short-term advantages with at least the same oncological long-term survival [6-9]. Portsite occurrenc- 
Table 4. Pathology data

\begin{tabular}{|c|c|c|c|}
\hline Variable & $\begin{array}{l}\text { Laparoscopic } \\
\text { TME }(\mathrm{n}=50)\end{array}$ & $\begin{array}{l}\text { Open TME } \\
(\mathrm{n}=50)\end{array}$ & $\mathrm{p}$ value \\
\hline Astler-Coller classifications ${ }^{1}$ & & & 0.58 \\
\hline A & $3(6)$ & $2(4)$ & \\
\hline B1 & $16(32)$ & $9(18)$ & \\
\hline B2 & $16(32)$ & $20(40)$ & \\
\hline $\mathrm{C} 1$ & $3(6)$ & $6(12)$ & \\
\hline $\mathrm{C} 2$ & $10(20)$ & $10(20)$ & \\
\hline $\mathrm{X}^{2}$ & $2(4)$ & $3(6)$ & \\
\hline \multicolumn{4}{|l|}{ Pathology outcomes ${ }^{3}$} \\
\hline Lymph nodes & $7(3-12)$ & $6(3-10)$ & 0.65 \\
\hline Anterior resections & $6(2-11)$ & $7(3.5-12.5)$ & 0.51 \\
\hline Abdominoperineal resections & $10(4-14.5)$ & $5(3-7)$ & $<0.05$ \\
\hline Resected bowel, cm & $22(18-28)$ & $28(23-34)$ & $<0.01$ \\
\hline Anterior resections & $21(17-25)$ & $26(21-30)$ & $<0.01$ \\
\hline Abdominoperineal resections & $27.5(20.5-35)$ & $36(30.5-39)$ & 0.09 \\
\hline Tumor diameter, $\mathrm{mm}$ & $25(20-37.5)$ & $40(25-50)$ & 0.01 \\
\hline Anterior resections & $30(20-40)$ & $40(23-50)$ & 0.15 \\
\hline Abdominoperineal resections & $20(15-30)$ & $40(32.5-45)$ & 0.01 \\
\hline Distal margin, $\mathrm{mm}$ & $30(20-50)$ & $32.5(20-47.5)$ & 0.61 \\
\hline Anterior resections & $30(15-40)$ & $30(20-45)$ & 0.43 \\
\hline Abdominoperineal resections & $45(20-55)$ & $40(30-47.5)$ & 0.762 \\
\hline Circumferential margin, $\mathrm{mm}$ & $6.5(4-11)$ & $8(5-16)$ & 0.16 \\
\hline Anterior resections & $7(6-15)$ & $12.5(6.5-15)$ & 0.18 \\
\hline Abdominoperineal resections & $4.5(3-10.5)$ & $5(3-8)$ & 0.61 \\
\hline Radical resection ${ }^{1}$ & $46(92)$ & $46(92)$ & 1.0 \\
\hline $\begin{array}{l}{ }^{1} \text { Values are shown as numbers } \\
{ }^{2} \text { Astler-Coller X: no malignan } \\
{ }^{3} \text { Values are shown as medians }\end{array}$ & $\begin{array}{l}\text { percentages in } \mathrm{p} \\
\text { or found after rac } \\
\text { interquartile ran }\end{array}$ & $\begin{array}{l}\text { entheses. } \\
\text { ation therapy. } \\
\text { s in parentheses }\end{array}$ & \\
\hline
\end{tabular}

es were as infrequent as incisional metastases in these studies, making it very likely that portsite metastases in earlier reports were due to technical failure rather than to inherent problems with laparoscopy.

Three factors have stimulated the development of laparoscopic surgery for rectal cancer. Firstly, the technical difficulty of rectal dissections in a narrow pelvis, especially in male patients. Secondly, the inherent benefit of improved fine instruments and the improved visualization provided by the laparoscopic camera during pelvic dissection. Thirdly, the possibility to better dissect the rectum up to the pelvic floor in order to perform a coloanal anastomosis, avoiding an abdominoperineal resection, in selected patients with very-low-rectal cancer.

In the series presented here, there were some differences in short-term outcomes between the laparoscopic and the open group. Although the length of hospital stay was equal for both groups, patients undergoing laparoscopic abdominoperineal resections were discharged sooner. In the laparoscopic group, enteric function returned sooner than in the open group. Although it took longer to perform a laparoscopic TME, it was accompanied by less blood loss and fewer operative complications. The major and minor complication rates were similar in both groups. However, major complications occurred in fewer patients in the laparoscopic group. Moreover, oncological resection (circumferential margin of $2 \mathrm{~mm}$ or more) does not appear to be compromised by the laparoscopic technique. The median number of lymph nodes harvested was below the 12 nodes suggested for adequate staging for both groups. This may well be explained by the high number of patients (26 for each group) receiving neoadjuvant radiation treatment followed by a long delay (average 6 weeks) to operation, which will reduce significantly the number of lymph nodes in the specimen. Although follow-up was short, the Kaplan-Meier survival curves showed no statistical difference on DFS and OS. The trend of better DFS and OS for the laparoscopic 


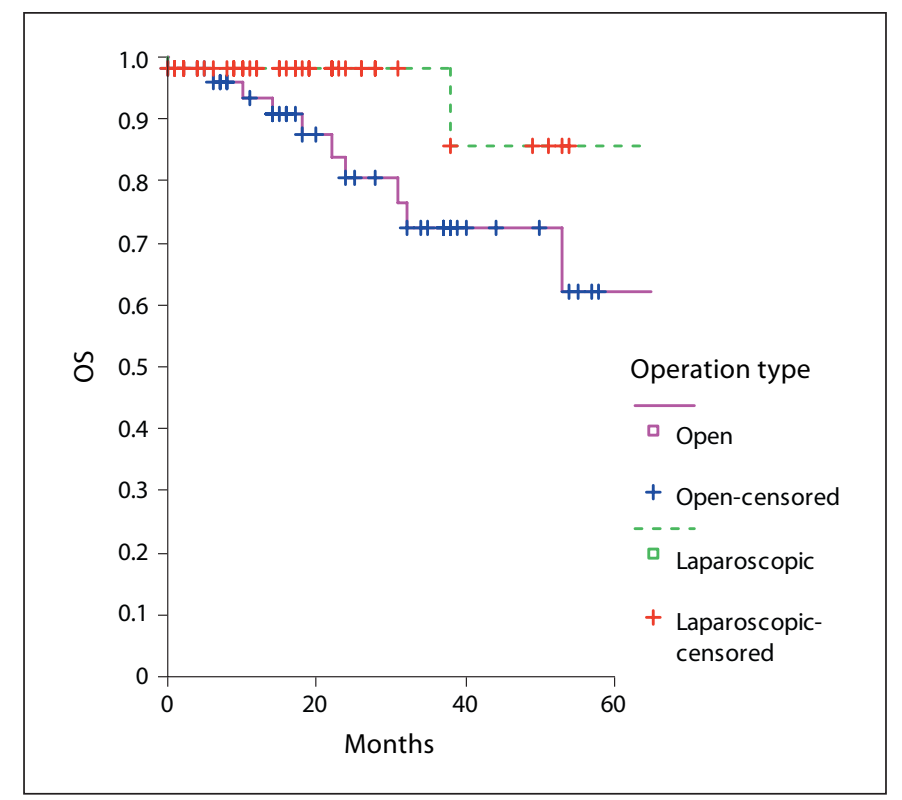

\begin{tabular}{|cll|}
\hline Months & \multicolumn{2}{l|}{ Patients at risk } \\
\cline { 2 - 3 } & Laparoscopic TME & Open TME \\
\hline 0 & 49 & 49 \\
20 & 19 & 25 \\
40 & 6 & 9 \\
60 & 1 & 1 \\
\hline
\end{tabular}

Fig. 1. Overall survival $(\mathrm{p}=0.08)$.

group may be explained by the smaller tumors found after pathology staging. On the other hand, local tumor infiltration showed no statistical difference, according to Astler-Coller classification, between the groups.

In contrast to the study by Quah et al. [16], which reported worse male sexual outcome in laparoscopically operated patients, recent feasibility and comparative studies, as well as a randomized series between open and laparoscopic TME by Leung et al. [17], have shown shortterm benefits to rectal cancer of the laparoscopic approach over the open approach, without compromising oncological outcome [17-22]. These studies reported mean operative times between 178 and 250 min with conversion rates between 10 and $23 \%$. Morbidity rates varied from 18 to $37 \%$ with mortality rates of up to $3 \%$. Mean hospital stay was reported to be between 7 and 12 days. These data are in line with the results of the present study. Reports on anastomotic leak rates have been widely divergent, ranging from $0.5 \%$ in the series of Leung et al.

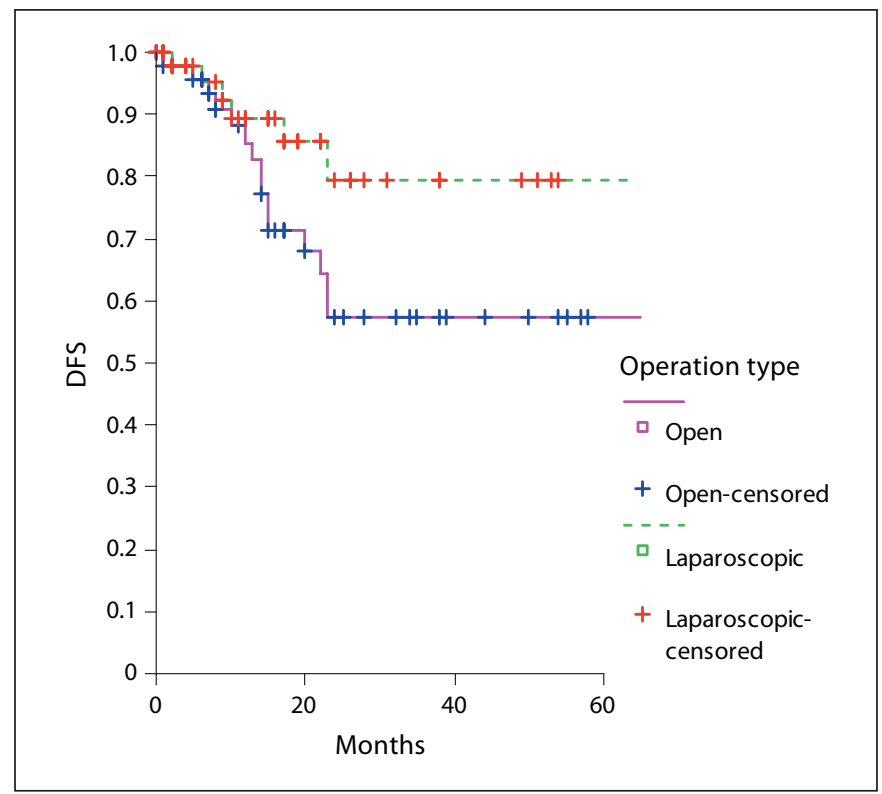

\begin{tabular}{|cll|}
\hline \multirow{2}{*}{ Months } & \multicolumn{2}{l|}{ Patients at risk } \\
\cline { 2 - 3 } & Laparoscopic TME & Open TME \\
\hline 0 & 49 & 49 \\
20 & 19 & 20 \\
40 & 6 & 8 \\
60 & 1 & 2 \\
\hline
\end{tabular}

Fig. 2. Disease-free survival $(\mathrm{p}=0.08)$.

[17] up to $17 \%$ in the series reported by Morino et al. [22] Long-term results on oncological outcome have shown survival rates between 76 and $85 \%$, which is in line with the data from the present study.

Interesting are the attempts to combine laparoscopic TME with a low or even ultralow anastomosis, and the different modalities in which this anastomosis can be fashioned. Important advances in this concept have been reported with acceptable morbidity rates and a good oncological outcome. Reliable data on functional outcome of patients with ultralow anastomosis are still few and far between. In the present series, 10 patients (20\%) received a coloanal anastomosis. In 2 female patients the anastomosis was converted to an end colostomy because of severe fecal incontinence. A coloanal anastomosis can be fashioned by double-stapled anastomosis through a Pfannenstiel incision, or by transanal anastomosis, which is manually performed end to end or by constructing a small J pouch. Techniques according to Parks or Basso or 
the intersphincteric approach are the most commonly used $[23,24]$. In this series the transanal anastomosis according to Basso was performed.

As the 'fast-track' multimodal recovery program is now being used more frequently in patients requiring surgery for colonic cancer, this may well soon be implemented in rectal surgery, subsequently reducing hospital stay even further. Surprisingly, no shorter hospital stay was found for the laparoscopic anterior resection group in the present study, although enteric function recovered sooner in the laparoscopic group. Possibly this was due to difficulties in learning adequate ileostomy care.

One final consideration has to be made about the patient diversity and consequently technical diversity. In most of the papers, the only technical distinction made is about the level of the tumor, but not about the difference between the male and female pelvis or other important factors such as neoadjuvant radiation therapy and body mass index. It is important to take these issues into consideration in further studies in order to stratify the results and permit comparison between series.

The operative and short-term advantages of laparoscopic TME have once more been shown by the present study. During surgery it seems that operating time is longer in the laparoscopic group with less blood loss. Important short-term advantages will be the quicker recovery of the bowel function with similar morbidity and mortality. Although follow-up is short, the laparoscopic approach to rectal cancer seems to allow an adequate oncological resection. Currently a multi-center randomized study, the COLOR II study, comparing laparoscopic TME to open TME, is well under way and will answer various questions regarding short-term outcomes and long-term survival.

\section{References}

1 Heald RJ, Husband EM, Ryall RDH: The mesorectum in cancer surgery: the clue to pelvic recurrence? Br J Surg 1982;69:613-616.

2 Heald RJ: Total mesorectal excision is optimal surgery for rectal cancer: a Scandinavian consensus. Br J Surg 1995;82:12971299.

3 Ridgway PF, Darzi AW: The role of total mesorectal excision in the management of rectal cancer. Cancer Control 2003;10:205211.

-4 Heald RJ, Karanjia ND: Results of radical surgery for rectal cancer. World J Surg 1992; 16:848-857.

5 Murty M, Enker WE, Martz J: Current status of total mesorectal excision and autonomic nerve preservation in rectal cancer. Semin Surg Oncol 2000;19:321-328.

-6 Lacy AM, García-Valdecasas JC, Delgado S, Castells A, Taurá P, Piqué JM, Visa J: Laparoscopy-assisted colectomy versus open colectomy for treatment of non-metastatic colon cancer: a randomised trial. Lancet 2002; 359:2224-2229.

-7 Nelson H, Sargent DJ, Wieand S, Fleshman J, Anvari M, Stryker SJ, Beart RW, Hellinger M, Flanagan R, Peters W, Ota D: A comparison of laparoscopically assisted and open colectomy for colon cancer. N Engl J Med 2004;350:2050-2059.

-8 The Colon Cancer Laparoscopic or Open Resection Study Group: Laparoscopic surgery versus open surgery for colon cancer: shortterm outcomes of a randomised trial. Lancet Oncol 2005;6:477-484.
-9 Weeks JC, Nelson H, Gelber S, Sargent D, Schroeder G: Short-term quality-of-life outcomes following laparoscopic-assisted colectomy vs open colectomy for colon cancer: a randomized trial. JAMA 2002;287:321-328.

10 Goligher JC: Surgery of the Anus, Rectum and Colon. London, Baillière Tindall, 1984.

$\checkmark 11$ Kapiteijn E, Marijnen CA, Nagtegaal ID, Putter H, Steup WH, Wiggers T, Rutten HJ, Pahlman L, Glimelius B, van Krieken JH, Leer JW, van de Velde CJ: Preoperative radiotherapy combined with total mesorectal excision for resectable rectal cancer. N Engl J Med 2001;345:638-646.

12 Jacobs M, Verdeja JC, Goldstein HS: Minimally invasive colon resection (laparoscopic colectomy). Surg Laparosc Endosc 1991;1: 144-150.

13 Berends FJ, Kazemier G, Bonjer HJ, Lange JF: Subcutaneous metastases after laparoscopic colectomy. Lancet 1994;344:58.

14 Lacy AM, Delgado S, García-Valdecasas JC, Castells A, Piqué JM, Grande L, Fuster J, Targarona EM, Pera M, Visa J: Port site metastases and recurrence after laparoscopic colectomy: a randomized trial. Surg Endosc 1998;12:1039-1042.

15 Wexner SD, Cohen SM: Port site metastases after laparoscopic colorectal surgery for cure of malignancy. Br J Surg 1995;82:295-298. 16 Quah HM, Jayne DG, Eu KW, Seow-Choen
F: Bladder and sexual dysfunction following laparoscopically assisted and conventional open mesorectal resection for cancer. $\mathrm{Br} \mathrm{J}$ Surg 2002;89:1551-1556.
7 Leung KL, Kwok SPY, Lam SCW, Lee JFY, Yiu RYC, Ng SSM, Lai PBS: Laparoscopic resection of rectosigmoid carcinoma: prospective randomized trial. Lancet 2004;363: 1187-1192.

18 Bretagnol F, Lelong B, Laurent C, Moutardier V, Rullier A, Monges G, Delpero JR, Rullier E: The oncological safety of laparoscopic total mesorectal excision with sphincter preservation for rectal carcinoma. Surg Endosc 2005;19:892-896.

19 Breukink SO, Pierie JPEN, Grond AJK, Hoff C, Wiggers T, Meijerink WJHJ: Laparoscopic versus open total mesorectal excision: a case-control study. Int J Colorectal Dis 2005; 20:428-433.

20 Delgado S, Momblán D, Salvador L, Bravo R, Castells A, Ibarzabal A, Piqué JM, Lacy AM: Laparoscopic-assisted approach in rectal cancer patients: lessons learnt from $>200 \mathrm{pa}$ tients. Surg Endosc 2004;18:1457-1462.

21 Morino M, Giraudo G: Laparoscopic total mesorectal excision - the Turin experience. Recent Results Cancer Res 2005; 165:167179.

22 Morino M, Parini U, Giraudo G, Salval M, Brachet Contul RB, Garrone C: Laparoscopic total mesorectal excision: a consecutive series of 100 patients. Ann Surg 2003;237:335342 .

23 Basso N, Minervini S, Marcelli M: Modified abdominotransanal resection for cancer of the lower third of the rectum. Dis Colon Rectum 1987;30:641-643.

-24 Parks AG, Percy JP: Resection and sutured colo-anal anastomosis for rectal carcinoma. Br J Surg 1982;69:301-304. 